
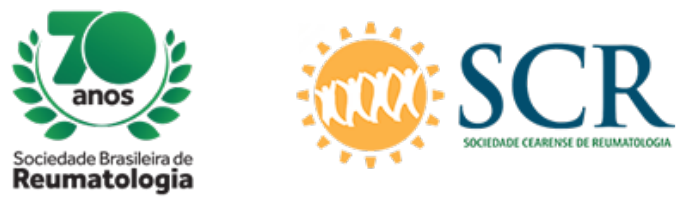

\title{
DIAGNOSTIC CHALLENGE OF A RARE INFECTIOUS DISEASE IN A PATIENT WITH CHRONIC WIDESPREAD PAIN CLASSIFIED AS FIBROMYALGIA - A CASE REPORT
}

Erivelton Azevedo Lopes (HCFMUSP, São paulo, SP, Brasil), Lorena Elizabeth Betancourt (HCFMUSP, São paulo, SP, Brasil), Mariely Fernanda Helbingen (HCFMUSP, São Paulo, SP, Brasil), Isabela Maria Bertoglio (HCFMUSP, São Paulo, SP, Brasil), Sergio Luiz Oliveira Nunes (HCFMUSP, São Paulo, SP, Brasil), Valdirene Silva Siqueira (HCFMUSP, São paulo, SP, Brasil), Lissiane Karine Noronha Guedes (HCFMUSP, São paulo, SP, Brasil), Eduardo Ferreira Borba (HCFMUSP, São Paulo, SP, Brasil), Luciana Parente Costa Seguro (HCFMUSP, São paulo, SP, Brasil), Rosa Maria Rodrigues Pereira (HCFMUSP, São Paulo, SP, Brasil), Diogo Souza Domiciano (HCFMUSP, São paulo, SP, Brasil), Marco Antonio Gonçalves Pontes Filho (HCFMUSP, São paulo, SP, Brasil)

\section{BACKGROUND}

Fibromialgya (FM) is a complex disorder, recognized as one of the most common chronic pain conditions. The pathophysiology underlying FM is still not entirely understood. However, there is currently convincing evidence that exits central sensitization, denoting that patients have an enhanced and/or amplified pain response to normally non-painful stimuli. Its diagnosis and treatment continue to be a challenge for the physicians, especially in particular cases, when it is difficult to differentiate infectious and/or inflammatory processes. We present herein one case report of a rare and chronic form of paraccocidiodomycose in a patient with FM.

\section{CASE REPORT}

A black 60-years-old male, with previous history of 10 years silicosis, was referred to our service due to widespread pain for 12 months. This symptom had worsened through walking, making impossible to perform activities of daily living. He reported moderate fatigue, unrepairable sleep, and some episodes of headache without warning signs. He complained of hyporexia from the onset of the condition without other gastric alterations, associated with weight loss of less than $10 \%$ of the total body weight, without symptoms suggestive of infection. During his first evaluation, he fulfilled the ACR 2010 Criteria for FM with a generalized pain index (GPI) of 15 points and a symptom severity scale (SS) of 10 points. Treatment was started based on selective serotonin reuptake inhibitor and common analgesic. Because of refractory pain symptom, it was added gabapentinoids and tramadol. After 4 weeks, the patient presented clinical improvement (GPI of 6 and SS of 5), but pain's localization only at lumbar region. At this moment, laboratory tests showed evidence of elevated acute phase reactants, and lumbar spine magnetic resonance revealed lithic lesion in the lower $L 4$ plateau with adjacent medullary edema. PET-SCAN denoted local hypercaption in L4-L5 vertebrae. Then, it was performed a bone biopsy, which exhibited paracoccidioidomycosis infection. He was treated with itraconazole, evolving with improvement of localized pain and better control of fibromyalgic symptoms.

\section{CONCLUSION}

FM represents the most common cause of chronic widespread musculoskeletal pain and it has been associated with multiples diseases. In our context, it was associated with a chronic rare infection - a diagnostic challenge. Therefore, all patients should be carefully evaluated during the diagnoses and treatment for different entities that could exacerbate FM symptoms. 